\title{
LAS RELACIONES ENTRE HERMANOS EN LA LEGISLACIÓN DE ALCANCE TERRITORIAL DE LA CASTILLA BAJOMEDIEVAL: DE LA PROTECCIÓN AL CONFLICTO ${ }^{1}$
}

\author{
FRATERNAL RELATIONSHIPS IN THE TERRITORIAL \\ LEGISLATION OF LATE MEDIEVAL CASTILE: \\ FROM PROTECTION TO CONFLICT
}

\author{
ROBERTO J. GONZÁLEZ ZALACAIN \\ Universidad del País Vasco, UPV/EHU
}

Resumen: Los estudios sobre la familia medieval en Castilla no han prestado especial atención a las relaciones intrafamiliares. Y cuando lo han hecho ha sido para analizarlas desde una perspectiva vertical, sin detenerse demasiado en comprender las que unieron a los hermanos y hermanas del medievo castellano. En este trabajo se propone una primera aproximación al tema analizando la legislación real castellana, tratando de delimitar el contenido social otorgado a la hermandad, así como las situaciones de protección o conflicto entre hermanos que se recogen en los textos normativos.

Palabras clave: hermanos y hermanas; derecho de familia; Castilla en la Baja Edad Media; familia medieval; conflictos familiares.

\begin{abstract}
Studies on the family in medieval Castile have not paid enough attention to relationships between family members. On the few occasions they have done so, the analysis has tended to focus on a vertical approach; consequently, little effort has been made to comprehend the ties between brothers and sisters in the Castilian Middle Ages. This paper aims to provide a closer look at this topic by means of an examination of Castilian royal legislation, trying to define the social content of brotherhood, as well as to reveal those fraternal liaisons concerning protection or conflict found in normative texts.
\end{abstract}

Keywords: brothers and sisters; family law; late medieval Castile; medieval family; family clashes.

1 Convocatoria para la concesión de ayudas de especialización para investigadores doctores en la UPV/EHU (2010). Grupo de Investigación Consolidado del Gobierno Vasco Sociedad, poder y Cultura (IT 322-10). Abreviaturas utilizadas: AGS-RGS = Archivo General de Simancas, Registro General del Sello; AChV-RE = Archivo de la Real Chancillería de Valladolid, Registro de Ejecutorias; FR = Fuero Real; $\mathrm{LT}=$ Leyes de Toro; $\mathrm{E}=$ Espéculo; $\mathrm{FVC}=$ Fuero Viejo de Castilla; $\mathrm{OA}=$ Ordenamiento de Alcalá; P, = Código de las Siete Partidas. 


\section{SUMARIO}

1. Introducción.- 2. La Historia de la familia en España, la familia medieval, el conflicto y las relaciones intrafamiliares. - 3. La definición de la relación de hermandad.- 4. La protección de los hermanos (y de las hermanas).- 5. La fuente de conflicto familiar.- 6. Conclusiones.- 7. Bibliografía citada.

\section{INTRODUCCIÓN}

Hace unos pocos años vio la luz un interesante monográfico de la revista Médiévales titulado Frères et soeurs, Ethnographie d'un lien de parenté. En el artículo introductorio el coordinador del volumen, Didier Lett, planteaba desde el propio título el estado de los estudios sobre este tipo de relación parental en la historiografía europea sobre la familia. Hablaba Lett de los hermanos y hermanas como los "parientes pobres" de la parentela ${ }^{2}$, incidiendo en la escasa atención mostrada por la historia de la familia a estas relaciones de parentesco, esenciales por otra parte para comprender el funcionamiento social de las células familiares.

Incidía con ello en una realidad evidente. Desde el advenimiento de la demografía histórica a mediados del siglo pasado el análisis de la familia y su incidencia en la configuración de la sociedad tuvo un intenso y extenso recorrido a partir de diversas posturas metodológicas diferentes. Partiendo del inicial desarrollo de los estudios sobre la vida familiar y la extensión de las estructuras familiares, siguió, desde hace unas dos décadas, un enriquecimiento del panorama de estudios que trajo aparejado el examen de los vínculos familiares o el estudio de las trayectorias individuales, con lo que se ha ampliado considerablemente el panorama de nuestro conocimiento sobre la familia en época histórica. Sin embargo, en todo este recorrido historiográfico las relaciones fraternales no han merecido la misma atención que otros de los vínculos, salvo honrosas excepciones ${ }^{3}$.

Veremos a continuación que para el caso español, y más concretamente el de la Castilla bajomedieval, esta escasa atención recibida se hace más evidente, y revela la necesidad de acometer el estudio en profundidad de esta relación desde múltiples vertientes. Por ello en las páginas que siguen se

${ }^{2}$ D. Lett, Les frères et les sœurs.

3 Ibidem. Además, está en preparación la publicación del coloquio internacional Frères et soeurs. Du moyen Age a nous jours, coordinado por Fabrice Boudjaaba, Christine Dousset y Sylvie Mouysset, y que verá la luz en un futuro próximo en la editorial Peter Lang. Para el caso británico contamos con alguna aproximación de interés a partir de la literatura, como la de M. Howard, 'We are broderen': Fraternal Bonds. 
propone el primer paso que ha de darse para un estudio de la relación entre hermanos y hermanas a fines de la Edad Media, el de su codificación en las normas legislativas de la época. En ellas encontramos información en tres direcciones: definiciones de hermandad, escenarios de apoyo entre hermanos, y posibles conflictos fraternales.

\section{LA HISTORIA DE LA FAMILIA EN ESPAÑA, LA FAMILIA MEDIEVAL, EL CONFLICTO Y LAS RELACIONES INTRAFAMILIARES}

Los medievalistas que se han acercado al estudio de las relaciones de parentesco en el Medievo castellano lo han hecho, salvo casos muy con$\operatorname{cretos}^{4}$, de una manera parcial, como método de aproximación destinado a desentrañar otros objetivos de investigación más amplios. Abundando más en esta afirmación, hay que señalar que dentro de estos estudios no se ha prestado excesivo interés a las relaciones intrafamiliares de la sociedad de la época. Su producción ha ido orientada fundamentalmente a desentrañar el papel, esencial por otra parte, que el parentesco y las relaciones familiares tuvieron en la constitución de las oligarquías locales ${ }^{5}$ y en el funcionamiento de los linajes nobiliarios ${ }^{6}$.

Por otro lado, conviene señalar que la corriente historiográfica que se conoce como historia de la familia se ha desarrollado de manera notable en España en los últimos años. Sin embargo, son pocos los estudios que se han elaborado sobre dos de los ejes que más nos interesan para conocer mejor las relaciones entre hermanos en la Castilla bajomedieval: la familia en la Edad Media, y el conflicto familiar?

4 Representados fundamentalmente por una serie de títulos editados por el CSIC en la última década del siglo pasado: I. Beceiro, R. Córdoba, Parentesco, poder y mentalidad; R. Pastor, (Comp.), Relaciones de poder, de producción; R. Pastor et al., Poder monástico y grupos domésticos en la Galicia foral.

5 Véanse los ejemplos de J.A. Solórzano, Linaje, comunidad y poder; V. Muñoz, La participación política de las elites; M. Diago, El papel de los linajes. Han de incluirse en este capítulo también aquellos trabajos dedicados a relativizar el papel del parentesco en la configuración del sistema de linajes urbanos castellano, subordinándolo a la operatividad de las estructuras políticas y sociales de los concejos. J.M Monsalvo, Parentesco y sistema concejil.

6 Sin ánimo de ser exhaustivos al respecto, además del trabajo ya citado de Beceiro y Córdoba conviene tener presentes los trabajos de M.C. Gerbet, Las noblezas españolas de la Edad Media; idem, La nobleza en la corona de Castilla, y las más recientes aportaciones de P. Martínez Sopena, La prosopografía de la nobleza castellano-leonesa; idem, La aristocracia hispánica. Además, sirva como ejemplo del vigor que la utilización del parentesco para analizar el estamento nobiliario ha tenido hasta la actualidad el reciente trabajo de I. Calderón, "Cum magnatibus Regni Mei”. La nobleza.

7 Con alguna honrosa excepción en ambos casos, como por ejemplo: E. Montanos, $L a$ familia en la Alta Edad Media; J. Casey, La conflictividad; J.I. Iglesia (coord.), La familia en 
Lo primero se explica por la ya mencionada imbricación que tuvo en sus orígenes esta vertiente de análisis con la demografía histórica, lo que excluía al mundo medieval castellano de los discursos planteados, ya que éste carecía de las fuentes de archivo necesarias para aplicar a este período las metodologías desarrolladas para las etapas siguientes ${ }^{8}$. Y en cuanto a la segunda cuestión, la historia de la familia ha desarrollado importantes estudios que han demostrado, ya sea a través de las genealogías sociales, ya con los análisis de redes sociales, el valor fundamental del parentesco en la estructuración de las sociedades de las épocas mencionadas, lo que le ha llevado a buscar de manera mucho más notable las relaciones familiares positivas, las que estructuraban en su entorno a la sociedad preliberal, que los posibles comportamientos disonantes con la práctica cultural mayoritaria9.

Por ello, y en la línea de otros trabajos que ya se están empezando a apuntar para otros contextos geográficos ${ }^{10}$, parece oportuno valorar en sus justos términos la posible conflictividad que se generaba en el interior de las familias, y con ello poder determinar en mejor medida también el grado de operatividad que esas relaciones familiares tuvieron en la articulación de la sociedad de la época.

En relación a las familias medievales se pueden distinguir dos esferas de conflicto diferentes. Por un lado, hay toda una vertiente externa al grupo familiar, manifestada en ataques a la honra y el honor, al patrimonio, o derivadas de conflictos políticos ${ }^{11}$, y hay otro tipo de relación, la que se genera en el seno de la familia, que es mucho más complicada de aprehender. En el seno del hogar, la autoridad del cabeza de familia, sancionada por la ley y la

la Edad Media. Para un contexto geográfico concreto véase J.R. Díaz de Durana, La familia en la cornisa.

8 Aunque A. Guerreau-Jalabert haya planteado sus dudas al respecto de la validez de ese argumento. A. Guerreau-Jalabert, El sistema de parentesco medieval, p. 87.

9 Basten como ejemplo de ambas cuestiones mencionadas las dos principales monografías publicadas en España sobre historia de la familia en los últimos años: J. Bestard, F. Chacón, (dirs.), Familias: historia de la sociedad española; F. García (coord.), Historia de la familia en la Península Ibérica. La primera apenas dedica sesenta de sus más de mil doscientas páginas al estudio de la España medieval cristiana, y no hay ningún apartado específico dedicado al estudio del conflicto familiar. En el segundo caso, el balance historiográfico planteado muestra el escaso peso del estudio sobre la familia medieval en el discurso historiográfico de esta especialidad.

10 M. Aurell (ed.), La Parenté déchirée. La obra coordinada por I. Davis, M. Müller, S. Rees Jones (eds.), Love, Marriage, contiene una serie de trabajos de gran interés en este sentido, como son por ejemplo el de P.C.M. Hoppenbrouwers, Vengeance Is Ours?; S. Bernardsky, Keeping It in the Family?, pp. 277-297; M.A. Brozyna, Not Just a Family Affair; M. Müller, Conflict, Strife, and Cooperation.

Para el caso castellano, se encuentra en proceso de edición la tesis doctoral de quien suscribe estas páginas, dedicada precisamente al conflicto familiar en la Castilla bajomedieval. R. González, La familia en Castilla en la Baja Edad Media.

11 Véase el ejemplo del País Vasco bien estudiado por A. Dacosta, Los linajes de Bizkaia. 
costumbre, le permitía ejercer el control sobre los restantes miembros de la casa, utilizando para ello la violencia si fuera necesario.

Sin embargo, este tipo de relaciones apenas dejan reflejo en las fuentes, y son merecedoras de un análisis exhaustivo en distintos planos, en buena medida aún por hacer. Las pocas ocasiones en que se ha dedicado algo de espacio en las monografías sobre la familia medieval a la relaciones intrafamiliares ha sido para analizar las que recorren transgeneracionalmente la familia, privilegiando de esta manera los estudios sobre las relaciones entre padres e hijos, sin prestar apenas atención a los lazos intergeneracionales, como el que constituyen hermanos y hermanas.

Este análisis de la línea horizontal de la genealogía puede ofrecer unos resultados muy interesantes si se afronta desde la perspectiva del conflicto, ya que en su narración encontramos la norma y su ruptura, la costumbre y la actuación contra ella. Por ello este trabajo busca ahondar en los conflictos derivados de la relación fraternal, como manera de conocer cómo entendía la sociedad bajomedieval que debía ser esa relación, y cómo eran en realidad.

\section{LA DEFINICIÓN DE LA RELACIÓN DE HERMANDAD}

Como acabo de indicar, el primer paso de un análisis de las relaciones fraternales ha de pasar necesariamente por la definición jurídica y cultural de los múltiples aspectos que afectan a este vínculo familiar en las recopilaciones de leyes del período. Una vez establecidos esos límites conceptuales veremos ya las distintas situaciones en las que las relaciones entre hermanos se movían entre la protección y el conflicto.

Será en las recopilaciones legislativas realizadas bajo el impulso de la corona en las que encontramos las más importantes referencias al conjunto de temas que afectaban de una manera u otra a la familia. Desde que en torno a mediados del siglo XIII se recopilara el derecho castellano del momento en el Fuero Viejo de Castilla ${ }^{12}$, hasta que en 1505 se promulgaran las Leyes de Toro, son varias las recopilaciones legislativas que de una manera u otra trataron temas concernientes al derecho de familia ${ }^{13}$. Entre esos dos extremos crono-

12 Recopilación legislativa que consta de cinco libros, a su vez divididos en títulos y leyes. Se citará de la siguiente manera: Abreviatura (FVC), Libro ${ }^{\circ}$, Título ${ }^{\circ}$, Ley $^{\circ}$. Se ha utilizado la edición El Fuero Viejo de Castilla, sacado y comprobado con el ejemplar de la misma obra que existe en la real biblioteca de esta corte, y con otros mss.

13 Para una primera aproximación a la evolución del derecho en el medievo castellano se pueden consultar las obras de J. Alvarado et al. Manual de Historia del Derecho, y R. Morán, Materiales para un curso de Historia, planteadas desde dos posturas teóricas diferentes. 
lógicos se redactaron, a su vez, el Fuero Real ${ }^{14}$ y el Ordenamiento de Alcalá15. Pero es en otra de las compilaciones de leyes más tempranas, la que recibe el nombre de las Siete Partidas ${ }^{16}$, de Alfonso X el Sabio, en la que encontramos un tratamiento más extenso de muchos de los temas que afectaban a las familias en la doble vertiente, externa e interna, a la que ya me he referido con anterioridad. Además, también durante su reinado se redactó el Espéculo ${ }^{17}$, obra de contenido muy similar a las Partidas.

Debemos tener presente, para una correcta comprensión global del tema que nos ocupa, que es precisamente en estos momentos en los que se está produciendo un doble proceso de codificación de la legislación previa, a la par que se va materializando la recepción del Ius commune o Derecho común, una cultura jurídica resultante de la conjunción del Derecho Romano justinianeo, del Derecho canónico y del Derecho feudal ${ }^{18}$. Ello generará un tipo específico de norma jurídica con notables semejanzas a los de otros contextos europeos, que hará que resulte muy interesante conocer precisamente las divergencias entre las distintas normas jurídicas de los diferentes reinos europeos ${ }^{19}$.

Comenzando ya con las notas referidas a la definición de hermandad que encontramos en todo este conjunto de obras legislativas castellanas hay que advertir que se maneja un concepto esencialmente biologicista, y se establece la relación entre hermanos de una manera natural, como la derivada de

14 Está estructurado en cuatro libros, a su vez divididos en títulos y éstos en leyes. Se citará siguiendo el siguiente esquema: Abreviatura (FR), Libro $n^{\circ}$, Título $n^{\circ}$, Ley $^{\circ}$. Se ha utilizado la edición Opúsculos legales del rey Alfonso X el Sabio, publicados y cotejados con varios códices antiguos por la Real Academia de la Historia. Vol. 1: El espéculo o espejo de todos los derechos; Vol. 2: El fuero real.

15 Consta de 32 títulos, divididos en leyes. Se citará: Abreviatura (OA), Título no ${ }^{\circ}$ Ley no . Se ha utilizado la edición El ordenamiento de leyes que D. Alfonso XI hizo en las Cortes de Alcalá de Henares el año de mil trescientos y quarenta y ocho.

16 Está compuesta por un prólogo y siete Partidas, que a su vez están divididas en títulos y leyes. Se citará siguiendo la siguiente estructura: Abreviatura (P), Partida ${ }^{\circ}$, Título $n^{\circ}$, Ley $n^{\circ}$. Se ha utilizado la edición Las Siete Partidas del Rey Don Alfonso El Sabio, cotejadas con varios códices antiguos por la Real Academia de la Historia.

17 Obra compuesta por cinco libros, a su vez divididos en títulos y leyes. Se citará: Abreviatura (E), Libro ${ }^{\circ}$, Título $\mathrm{n}^{\circ}$, Ley $\mathrm{n}^{\circ}$. Se ha utilizado la edición Opúsculos legales del rey Alfonso X el Sabio, publicados y cotejados con varios códices antiguos por la Real Academia de la Historia. Vol. 1: El espéculo o espejo de todos los derechos; Vol. 2: El fuero real.

18 R. Morán, Materiales para un curso de Historia, pp. 511 y ss.

19 Esa labor excede las pretensiones de este trabajo. Si el lector está interesado en conocer mejor otros contextos, a la bibiliografía citada a la lo largo del artículo se le puede sumar la consulta del trabajo de A. Guerreau-Jalabert, Sur les structures de parenté dans l'Europe médiévale, en el que hace una crítica desde diversos puntos de vista, incluyendo el de la concepción del matrimonio y su definición normativa, a una serie de trabajos anteriores, como por ejemplo el de G. Duby, J. Le Goff (dirs.), Famille et parenté dans l'Occident médiéval. También es interesante, por las aportaciones de diversas realidades de la Europa premoderna que contiene, la obra R. Ganghofer (dir.), Le droit de la famille en Europe. 
compartir progenitores. Apenas hay reflexiones o explicaciones al respecto, y cuando aparecen lo hacen habitualmente asociadas a la relación entre hermanastros a cuenta del reparto de la herencia, como tendremos ocasión de comprobar más adelante.

Uno de los escasos ejemplos en los que podemos entresacar información de este tipo lo tenemos en las Partidas, en las que encontramos englobada la definición de la hermandad a partir de la ubicación de los miembros en el entramado genealógico:

En qué manera deben ser contados los grados del parentesco, et fasta qué grado non se pueden ayuntar para casar.

Cuenta et departe santa eglesia que son quatro grados en el parentesco, et muestra que se deben contar de esta manera: en la liña derecha que sube arriba son en el primero grado padre et madre, en el segundo abuelo et abuela, en el tercero visabuelo et visabuela, en el quarto trasabuelo et trasabuela. Et en la liña que decende derecha á yuso son en el primero grado fijo et fija, en el segundo nieto et nieta, en el tercero visnieto et visnieta, en el quarto trasvisnieto et trasvisnieta. Et en la liña de travieso son en el primero grado hermano et hermana, en el segundo fijos de hermano et de hermana, en el tercero nietos et nietas de hermano et de hermana, en el quarto visnietos et visnietas de hermano et de hermana. En los grados de las liñas que suben ó decenden derechamiente, nunca pueden casar quanto quier que sean alongados unos de otros: mas en las liñas que son de travieso pueden casar los de una parte con los de la otra del quarto grado pasado en adelante ${ }^{20}$.

Queda clara la evidencia de que la relación de hermandad se ubica en un lugar preferente en la consideración jurídica y cultural de la época. Esta idea queda reforzada con algunos ejemplos dispersos que aparecen en las Partidas relativos a otros temas, y que utilizan los lazos fraternales como argumento de refuerzo de la idea que se quiere transmitir. De esta forma, cuando se nos introduce en la definición de los distintos tipos de guerra ${ }^{21}$, se exponen las características básicas de la llamada guerra plus quam civilis, la que llevaban a cabo los parientes entre ellos. El mejor ejemplo que encontró el legislador fue la segunda guerra civil de la República Romana, entre Cesar et Pompeyo, que eran suegro et yerno, en qual guerra los romanos guerreaban los padres contra los fijos, et los hermanos contra los hermanos, teniéndose los unos con Cesar et los otros con Pompeyo. Como vemos, a la hora de dimensionar las relaciones familiares se utilizan los dos ejes, el vertical y el horizontal,

20 P, IV, VI, LEY IV.

21 P, II, XXIII, LEY I. "Qué cosa es guerra y quántas maneras son dellas". 
citándose expresamente a los hermanos por la fuerza simbólica que comporta esta relación.

La condición de hermandad también es contemplada en algunos de los supuestos que dedica la legislación alfonsí a la legitimación de hijos naturales, un hecho jurídico de gran relevancia en la documentación de la época $^{22}$. Así, se señala explícitamente que en el caso de que la persona afectada tenga varios hijos naturales con la misma amiga, y sólo reconozca a uno de ellos, este reconocimiento se hará extensivo inmediatamente a los demás hermanos ${ }^{23}$.

En otro momento de esta misma recopilación legislativa se profundiza en las distintas posibilidades de hermandad entre hijos no legitimados, especialmente en el caso de que se comparta padre y no madre -o ese extremo no esté seguro-, ya que hechos de ese tipo influyen notoriamente a la hora de determinar derechos sucesorios de las personas, fuente principal de conflictos en la época, como veremos después ${ }^{24}$.

Una vez establecida la descripción de la línea de parentesco conviene ir dotando de contenido cultural al vínculo entre hermanos. En ese plano, y manteniéndonos dentro de las disposiciones de las Partidas, encontramos en la ley II del título I de la séptima Partida, en la que se recoge un listado bastante exhaustivo de personas incapacitadas para denunciar, se indica expresamente que no puede acusar el hermano a sus hermanos, detalle ilustrativo del grado de intimidad establecido a partir de la fraternidad ${ }^{25}$.

22 J. Martínez, En la definición de hijo natural.

${ }^{23}$ P, IV, XVI, LEY VII. "En qué manera pueden los padres legitimar sus fijos por carta. (...) Otrosi quando alguno que ha muchos fijos naturales de una amiga, et conosce al uno dellos tan solamiente por su fijo, por tal carta et en tal manera como sobredicha es en esta ley, por tal conoscimiento como este serán legitimos los otros hermanos, quanto por heredar en los bienes del padre, tambien como aquel en cuyo nombre fue fecha la carta, maguer non fuesen nombrados en ella".

24 P, VI, XIV, LEY XII. "En qué manera pueden heredar entre si los hermanos que son dichos naturales. Fijo natural que non es nascido de legítimo matrimonio, si moriese sin testamento non habiendo fijos, nin nietos nin madre, entonce sus hermanos quel pertenescen de parte de su madre deben haber todo lo suyo; et si otros hermanos hobiere de parte de su padre tan solamiente, non heredarán ende ninguna cosa, et esto es porque los hermanos quel pertenescen de parte de su madre son ciertos et los departe del padre son en dubda. Mas si este fijo natural que moriese sin testamento hobiese otros hermanos naturales quel pertenesciesen de su padre tan solamiente, et non hobiese de los otros que fuesen nascidos de su madre como él, entonce estos atales bien heredarien lo suyo, porque son los más cercanos parientes, fueras ende si el que asi moriese hobiese hermano natural et legítimo de parte de su padre; ca entonce este ha mayor derecho en la herencia que los otros naturales que son sus hermanos de parte del padre tan solamiente".

25 En la Partida III se detallan cuáles son las excepciones a esa norma:

P, III, II, LEY IV. "Sobre quáles pleytos puede mover demanda en juicio un hermano contra otro et sobre quales non. Hermano contra hermano non puede facer demanda en juicio sobre cosa por que debiese rescebir muerte, ó perdimiento de miembro ó seer hechado de la tierra, 
Esta estrecha relación derivada del parentesco fraternal se muestra también muy claramente a través de otra ley que especificaba que no podía testificar en pleito un hermano a favor del otro siempre que vivieran bajo el mismo techo ${ }^{26}$, hecho éste que redunda en la importancia del lazo, reforzado en este caso con el argumento de la corresidencia.

Otro detalle que ayuda a definir el contenido positivo de esas relaciones entre hermanos y hermanas lo encontramos en la mención que se hace a que las hermanas podían vivir con sus hermanos clérigos, bajo su mismo techo, sin temor a que esa situación fuera denunciada por atentar contra la moralidad, con el argumento explícito de que la cercanía en el parentesco ahuyentaba cualquier sospecha a esa cohabitación ${ }^{27}$.

También podemos apuntar en esta misma línea argumental un trazo en negativo, ya que tenemos noticias sobre la potestad de un padre para matar a su hijo en caso de que estuviera yaciendo con su hermana, y por ende rompiendo incestuosamente esta concepción positiva básica de la relación entre hermanos:

Sy el padre en su casa fallare alguno con su fija, o el hermano con la hermana, que non aya padre nin madre, o el pariente propinco que en su casa la toviere, puedala matar sin pena si quisiere, e a

fueras ende si lo ficiese por fecho que tanxiese a él mismo asi como si el otro se trabajase de lo matar por si o por otri, o de facerle perder miembro, o de otra cosa que se le tornase en deshonra muy grande, ó si lo quisiere desheredar sin derecho, o por muerte de señor que lo hobiese muerto a trayción non habiendo otri que lo demandase, o por fecho de otra trayción muy grande que tanxiese al rey o al regno".

En el Fuero Real también se trata este mismo asunto, aunque en el desarrollo discursivo prevalece la relación de parentesco vertical frente a la horizontal:

FR, II, VIII, 9: "Padres, fijos, nietos, Viznietos, hermanos, sobrinos, primos, fijos de hermanos, sobrinos fijos de primos, segundos cormanos, tios que son hermanos o primos de padre o de madre, non sean testimonias contra estraños, fuera si fuer en pleito que sea entre parientes e parientes de egualeza".

26 P, III, XVI, LEY XV. "Que non puede testiguar la muger por su marido, nin el hermano por su hermano.

Muger non puede testiguar por su marido en juicio, nin el marido por su muger en pleyto que ellos, nin el marido por su muger en pleyto que ellos demandasen: eso mesmo decimos en hermano por hermano non podrie dar testimonio en juicio mientre que ambos estodiesen en poder de su padre, et vivieren de so uno habiendo sus cosas comunalmente, mas despues bien lo podrien facer".

27 P, I, V, LEY XXXVII. "Que los clérigos deben ser honestos, et quales mugeres pueden con ellos morar (...) quales mugeres podiesen con ellos morar sin mala estancia, et son estas: et tia hermana de padre ó de madre, sobrina fija de hermano ó de hermana, su fija mesma que hobiese madre, et abuela, et hermana habido de muger de bendiciones ante que recibiese órden sagrada, ó su nuera muger velada de su fijo legítimo ó otra que fuese su parienta en segundo grado, asi como prima cormana. Estas pueden morar con ellos por esta razon, porque la natura del parentesco es tan acercada entre ellos que face á los homes que non deben sospechar mal: et como quier que tales parientas como estas sobredichas puedan tener consigo, non deben ellas tener otras mugeres de quien podiesen sospechar que feciesen yerro con ellas los clérigos". 
aquel que con ella fallare, e pueda matar al uno dellos si quisiere, e dexar el otro ${ }^{28}$.

Hemos visto cómo se dedica una ley de las Partidas a detallar los grados de parentesco sanguíneo. Para completar la descripción del universo del parentesco cristiano medieval hay que tener en cuenta el otro gran eje articulado por la sociedad de la época, el espiritual. Éste también tiene un espacio en la legislación, describiéndose con detalle los límites la vinculación derivada del padrinazgo. A este respecto, para el tema que nos ocupa se ha de destacar que se especifica muy claramente que las relaciones de parentesco se entablan únicamente entre padrino y ahijado, por lo que en cualquier circunstancia puede ese padrino casarse con alguno de los hermanos o hermanas de su pariente espiritual ${ }^{29}$.

Por último, no debemos olvidar la relación de parentesco establecida a partir de la hermandad que conjuga la línea horizontal con la vertical, es decir, las distintas posibilidades de relación entre tíos y sobrinos. Al respecto no hay muchas menciones en la legislación, pero las que aparecen son bastante significativas. Véase, por ejemplo, lo que dice el Fuero Real al hablar de las herencias de los tíos:

Sy el que moriere sin manda e sin herederos naturales oviere sobrinos fijos de hermano o de hermana por mas propincos, todos partan la buena del tio o de la tia por cabezas, maguer que los sobrinos del un hermano sean mas que del otro, ca pues iguales son en el grado, eguales deben seer en la particion. Et esto mismo sea de los primos, o dent ayuso, que ovieren derecho de heredar lo del muerto ${ }^{30}$.

28 FR, IV, VII, 6.

29 P, IV, VII, LEY V. "Qué Repartimiento ha entre el parentesco espiritual, et el carnal et de cuñadía para non embargar el casamiento. Non han semejanza el parentesco espiritual con el parentesco carnal et de cuñadia: et esto es porque en el parentesco carnal et de cuñadia ha quatro grados fasta que non puede ningunt home nin muger casar con su pariente nin con su parienta, nin con su cuñado nin con su cuñada. Mas porque en el parentesco espiritual non ha grado ninguno, por ende bien puede el padrino ó la madrina casar con el fijo ó con la fija de su afijado ó de su afijada. Otrosi bien puede casar el padrino ó la madrina con hermana ó con hermano de su afijado ó de su afijada:et esto es porquel padrino nin la madrina non han parentesco con los fijos nin con las fijas de sus compadres nin de sus comadres, sinon con aquellos que son sus afijados ó sus afijadas, nin otrosi con los hermanos nin con las hermanas de sus afijados nin de sus afijadas, mas solamiente con sus afijados ó con sus afijadas, 6 con sus compadres ó con sus comadres. Et por ende ningunt home nin muger de los sobredichos non puede casar con aquel ó con aquella con quien hobiese parentesco espiritual".

Esta disposición se enmarca en un marco cultural general que afecta al conjunto de la cristiandad europea, impulsado en buena medida por por los pensadores eclesiásticos, y materializado en sus aspectos esenciales en el IV Concilio de Letrá. Para comprender en toda su extensión el proceso es esencial la consulta de la obra de J. Brundage, La Ley, el sexo y la sociedad cristiana, especialmente entre las páginas 333 y 417.

30 FR, III, VI, XIII. 
Como vemos, con la ayuda de la legislación apenas podemos pasar de realizar un somero esbozo de lo que debía representar el parentesco entre hermanos para los hombres y mujeres del medievo. La lectura de los textos nos refiere un universo de sobreentendidos, que no requieren de mayor codificación para que las personas sobre las que actúan estas leyes sepan a qué se refieren. Ahora bien, como tendremos la oportunidad de ver a continuación, el análisis de situaciones concretas planteadas por la legislación sí nos permite profundizar más en el contenido cultural que el vínculo de parentesco entre hermanos tenía para la sociedad castellana de la época.

\section{LA PROTECCIÓN DE LOS HERMANOS (Y DE LAS HERMANAS)}

Comencemos esta descripción de los valores asociados a la relación entre hermanos buscando las caracterizaciones positivas de la misma. A este respecto, el primer detalle que merece la pena destacarse es que una de las imágenes que en este sentido tienen más fuerza en varias de las recopilaciones legislativas analizadas es la que resalta el papel del primogénito en el entramado familiar, especialmente si por alguna circunstancia se produce el fallecimiento de los padres. En ese momento, las Partidas señalan que el hermano mayor ha de hacer frente a la situación y encargarse de sus hermanos y hermanas menores ${ }^{31}$, algo que parece que tuvo correspondencia en la realidad, al menos entre las familias nobles ${ }^{32}$.

Ya en el Fuero Real se especificaban hechos parecidos, en los que los miembros de la familia que estuvieran en condiciones debían cuidar de los que lo necesitaran, y haciendo especial mención a los hermanos:

Si el padre o la madre vinieren a pobreza en vida de los fijos, quier sean casados quier non, mandamos que segund fuere su poder de cada uno, que govierne al padre e a la madre. Otrosi mandamos, que si ovieren algun hermano que fuere pobre, sean tenudos del governar: et si el padre o la madre moriere, los fijos goviernen a aquel que fincare et si se casare, denle la meytad del govierno quel ante davan, e non sean tenudos de governar la madrastra si non quisieren ${ }^{33}$.

31 P, VI, XVI, LEY X. "Cómo aquel que aforra su siervo de menor edat debe seer guardador dél et de sus bienes si quisiere. (...) Otrosí decimos que si el padre saca al fijo de su poder que es menor de catorce años, que él le debe haber en guarda á él et á todos sus bienes; et si el padre moriese ante que el mozo fuese de edat, si el huérfano hobiese otro hermano que fuese mayor de veinte et cinco años, él le debe haber en guarda en logar de su padre".

32 I. Beceiro, R. Córdoba, Parentesco, poder y mentalidad, p. 286.

33 FR, III, VIII, 1. 
Este principio conceptual que identifica al primogénito con su padre en su ausencia se plasma de manera muy gráfica cuando se habla del derecho del primogénito a heredar el trono del rey, haciendo una definición teórica sobre lo que significa mayoría y el contenido del argumento que sustenta ese derecho ${ }^{34}$. La primogenitura ha sido uno de los aspectos que más ha interesado a los medievalistas del medievo castellano, ya que su progresiva definición y consolidación se enmarcaba en un proceso de consolidación de las estructuras nobiliarias en las que jugó un papel fundamental el reparto de la herencia ${ }^{35}$. Pero no debemos perder de vista que a esta perspectiva vertical debemos añadir la horizontal, ya que la primogenitura también genera relaciones específicas entre los hermanos, asignando a cada uno de ellos un estatuto diferenciado, de iure o de facto, en función de su posición en la línea genealógica o de su sexo.

Más allá del hermano mayor también encontramos otras menciones a la responsabilidad sobre lo que ocurra a otros hermanos, aunque en este caso suelen estar más referidas al papel custodio sobre la hermana ${ }^{36}$.

34 P, II, II, LEY II. "Cómo el fijo mayor del rey ha adelantamiento et mayoria sobre los otros sus hermanos. Mayoria en nascer primero es muy grant señal de amor que muestra Dios á los fijos de los reyes, á aquellos que la da entre los otros sus hermanos que nascen despues del (...). Et que los hermanos le deben tener en logar de padre se muestra porque él ha mas dias que ellos, et veno primero al mundo".

En P, II, XVII, LEY IX se refuerza esta idea del valor del primogénito sobre los restantes hermanos cuando se habla de cuáles son las cosas que debe enseñar un rey a sus descendientes: "Et otrosi les deben amostrar como amen et teman á su padre, et á su madre et á su hermano mayor, que son sus señores naturalmente por razon del linaje".

35 I. Beceiro, R. Córdoba, Parentesco, poder y mentalidad, pp. 41-108.

36 FVC, V, V, 2. "Esto es Fuero de Castiella: Que si alguna manceba en cauellos se casa o se va con algund ome, si non fuer con placer de suo padre, o de sua madre, si lo ouier, o con placer de suos ermanos, si los ouier, o con placer de suos parientes los mas cercanos, de ve ser deseredada, e puedela deseredar el ermano mayor, si ermanos ouier; e si ella fuer en tiempo de casar, e non ouier padre, o madre, e suos ermanos, o suos parientes non la quisieren casar por amor de eredar lo suo, deve ella mostrarlo en tres Viellas, o en mas, como es en tiempo de casar, e suos ermanos, o suos parientes non la quieren casar por amor de eredar lo suo, e de que lo ouier querellado e mostrado ansi como es derecho, e despues casare, non deve ser deseredada por derecho".

Encontramos una disposición parecida también en el Fuero Real, aunque el contenido temático de esta ley del Fuero Viejo de Castilla se divida en dos leyes diferentes.

Una se refiere a la obligación de tener el permiso de los padres, y por extensión de los hermanos, para contraer matrimonio (FR, III, I, 14): "Ninguno non sea osado de casar con manceba en cabellos sin placer de su padre o de su madre si los oviere si non, de los hermanos o de los parientes que la tovieren en poder; e aquel que lo ficiere peche $\mathrm{C}$ maravedis, la meytad al rey e la meytad al padre o a la madre si los oviere, si non, a quien la tiene en poder, e [demás] sea enemigo de sus parientes".

La otra parte hace alusión a los derechos de la mujer en el supuesto de que los hermanos no la quieran casar para poder seguir gestionando sus bienes (FR, III, I, 2): "Si el padre o la madre de alguna muger que sea en cabellos muriere, e alguno la pediere para casamiento a sus hermanos, e fuer tal que la muger e los hermanos sean entregados en él, e por malquerencia, o por cobdiçia de retener lo suyo, o por deseredarla si casare sin su mandado, e non la quisieren casar, e ella entendiendo aqueste engaño e afrontandogelo casare con él, o con otro que convenga a 
Este tipo de disposiciones refuerzan la figura del hermano varón como sustituto del padre, y por ende encargado de velar por la seguridad de sus hermanas jurídicamente expuestas. Por esta razón en algunas de las recopilaciones legislativas esta capacidad de desheredar que se menciona en el Fuero Viejo de Castilla no era aplicable al caso de las hermanas viudas, ya que el previo paso por el matrimonio modificaba su estatuto jurídico de cara al conjunto de la sociedad ${ }^{37}$.

Además, este ejercicio de autoridad también llevaba aparejadas una serie de obligaciones de los padres -y por extensión de los hermanos en ausencia de éstos-, ya que debían casar a sus hermanas antes de que ellas cumplieran los veinticinco años. En caso de no hacerlo ella podría casarse con quien quisiera, sin el consentimiento de sus hermanos ${ }^{38}$.

La responsabilidad para con las hermanas no se limitaba a las acciones punitivas que acabamos de observar, sino que se extendía a otros ámbitos de competencia familiar. Así, si los padres habían fallecido, recaía sobre los hermanos la responsabilidad de gestionar el cobro de las arras debidas en caso de que no hubieran sido abonadas ${ }^{39}$.

En definitiva, de estas situaciones que aluden a distintos escenarios de protección entre hermanos podemos extraer dos conclusiones fundamentales. Por un lado, uno de los objetivos fundamentales de la legislación es dotar de mecanismos de sustitución en el entramado familiar en el supuesto de que falte el cabeza de familia. Para ello, una de las caracterizaciones esenciales de la figura del hermano mayor nos lo presenta como un padre -en el sentido de poseedor de la patria potestad- en potencia.

En este contexto, la otra conclusión, derivada del análisis de género, revela que en este tratamiento de hermanos y hermanas no es gratuita la di-

ella e a sus parientes, los hermanos non la puedan deseredar por tal razon, fuera si aquel con qui casó era enemigo de sus hermanos, o les avie fecha alguna onta, ca por tal cosa como esta, maguer sea de tan buen derecho como ellos, non es derecho que case con él: et si lo ficiere, sea deseredada de la buena de su padre e de su madre".

37 FR, III, I, 3: "Si alguna muger biuda, o que haya avido señor o amigo, casare despues de muerte de su padre, e de su madre sin voluntad de sus hermanos, non sea desheredada por ello; ca pues quel sopieron aquel yerro, gelo sofrieron, non es razon que por el casamiento la deban desheredar".

38 FR, III, I, 6: "Si el padre o la madre, o hermanos o otros parientes tovieren en su poder manceba en cabellos, e non la casaren fasta xxv años, e ella despues casare sin su mandado, non aya pena por ende, casando ella con ome quel conviniere".

39 FR, III, II, 3: "Cuando el que casare diere arras a la manceba con quien casa, si ella non oviere xxv años, el padre o la madre de la manceba aya poder de guardar estas arras para su fija por que non se puedan vender ni enagenar. Et si padre o madre non oviere, los hermanos de la manceba o los otros mas propincos parientes ayan este poder, e cuando la manceba viniere a hedat de xxv años entreguengelas, e si arras non le dió luego, e gelas prometió de dar, estas personas las puedan demandar e guardar, asi como sobre dicho es; et entretanto la manceba e el marido vivan en los frutos comunalmente". 
ferenciación entre los dos sexos. A pesar de que en ningún momento se duda de que las hermanas tengan iguales derechos que los hermanos a heredar ${ }^{40}$, lo cierto es que a partir de esta serie de leyes seleccionadas podemos detectar que tanto el sexo como la posición en la línea de descendencia otorgaban, a ojos de los legisladores, diferentes papeles a cada uno de los miembros de la familia.

\section{LA FUENTE DE CONFLICTO FAMILIAR}

Si en el apartado anterior se ha trazado el retrato positivo de las relaciones fraternales, le corresponde ahora el turno a su contrario, a todo lo que se puede encuadrar dentro del capítulo de conflictividad familiar. Dentro de este apartado cabe destacarse la abrumadora mayoría de disposiciones referidas a cuestiones derivadas del reparto de la herencia, verdadera preocupación que recorre transversalmente toda la legislación castellana bajomedieval. Esta dedicación se corresponde de manera muy clara con la importancia de este tipo de conflictos en el conjunto de conflictos familiares de la época. Hay que tener en cuenta que, por ejemplo, el $35 \%$ de los pleitos que afectaban a la familia, movidos ante la Real Chancillería de Valladolid en el período comprendido entre los años 1475 y 1525, estaban relacionados de alguna manera con la herencia familiar ${ }^{41}$.

Si seguimos un orden cronológico en la exposición, ya desde el Fuero Viejo de Castilla encontramos alguna referencia explícita a conflictos derivados de la disputa de la herencia:

Que si un ermano a otro desereda, e non le quier dar particion de buena de padre, o de madre, o de otro pariente, quel pertenesca, e tienela forçada, e va a lo suo, do lo falla, e tomagelo por fuerça, e non quier dar, lo que a tomado, o en logar de dargelo aquello, tomal mas, el ermano, que esto rescive, devegelo mostrar la primera vegada ante parientes, e ante amigos Fijosdalgo el tuerto, quel face, e devel rogar ante ellos, que gel enderece, et que se parta del non facer mas aquel tuerto, e que non le tenga deseredado ${ }^{42}$.

40 Hecho ya constatado desde el Fuero Real. FR, III, VI, 10: "Quando alguno moriere sin manda, los hermanos egualmientre hereden con las hermanas, asi en la heredat del padre como de la madre, como de los otros parientes si son en egual grado".

${ }^{41}$ En concreto fueron 1.986 pleitos de un total de 5.776 ejecutorias relacionadas con conflictos familiares, lo que supone exactamente un $34,38 \%$. El número total de ejecutorias conservadas para ese período es de 18.262 documentos, lo que implica que el 10,87\% de las ejecutorias totales trata de un pleito por una herencia. R. González, La familia en Castilla en la Baja Edad Media.

42 FVC, I, V. 
En esta ley se recoge uno de los principales motivos de pleitos entre hermanos de la época, derivado de todas aquellas situaciones en que uno o varios de los hermanos retienen la totalidad del patrimonio de los padres para su propio uso, sin repartirlo como debieran entre todos los herederos legítimos. No debemos desligar este tipo de actuaciones con lo visto en el apartado anterior referido al papel otorgado a los primogénitos a la hora de cuidar de los demás hermanos. En muchas ocasiones serán estos hermanos mayores los que ocupen la herencia de los restantes herederos aprovechando la gestión realizada durante la minoría de edad de estos últimos $^{43}$.

No obstante, el grueso de las menciones a la herencia en relación al vínculo fraternal se refiere a la estipulación de las condiciones del reparto de los bienes. A lo largo de toda la Baja Edad Media se produce una constante interferencia entre la práctica jurídica que obliga a repartir los bienes de manera igualitaria entre los herederos, y la práctica social que trata de imponer un principio de primogenitura, si no sobre el conjunto de los bienes a repartir, sí sobre la parte principal de los bienes ${ }^{44}$.

Por ello nos encontramos también desde las primeras recopilaciones legislativas extensas disposiciones referidas a la propiedad de los bienes de cada uno de los hermanos, como se puede comprobar en el siguiente fragmento del Fuero Real:

Si el fijo que está con su padre o con su madre ante que case ganare alguna cosa por su trabaio, o quel dé el rey o su señor, o otro ome cualquier, non sea tenudo de dar parte a sus hermanos despues de muerte de su padre o de su madre, maguera gelo demanden a partir, fueras si lo ganó con el aver del padre o de la madre, e seyendo con el padre o con la madre, e governandose del aver del padre o de la madre. Et maguer se govierne de lo del padre o de lo de la madre, si con el a ver del padre o de la madre non lo ganare, non sea tenudo de lo dar a partir; ca padre o madre siempre es tenudo de governar sus fijos: mas si con el a ver del padre o de la madre ganare algo estando en poder de amos o de alguno dellos, el padre o la madre lo debe a ver todo, e despues de su muerte del padre o de la madre, ayan su parte los hermanos ${ }^{45}$.

43 La cantidad de ejemplos conservados en la documentación judicial es muy elevada, así que me limitaré a citar dos de ellos a modo de demostración: la denuncia que realiza ante la justicia Antón de Larrea, vecino de Bilbao, contra sus hermanos mayores, por usurpación de los bienes de la herencia (AGS-RGS, V-1498, f. 266), y el pleito seguido en 1524 por Catalina de Echave contra sus hermanos por la misma cuestión (AChV-RE, 372,53).

44 I. Beceiro, R. Córdoba, Parentesco, poder y mentalidad.La nobleza castellana.

45 FR, III, IV, 7. 
En esta ley se entremezclan varios conceptos esenciales a la hora de comprender el reparto de la herencia. Aparece el trabajo individual como manera de acceso a la propiedad, el matrimonio como hito vital fundamental que marca la estancia en casa con los padres, y el deber de repartir los bienes de los padres y los frutos obtenidos con su gestión con los restantes hermanos como trasfondo discursivo. En este caso, como en otros que iremos viendo a continuación, la legislación posterior, y más concretamente las Partidas, refrendarán lo dispuesto y en ocasiones lo explicitarán mejor para que no haya dudas $^{46}$.

También desde la promulgación del Fuero Real se trató de consolidar la transmisión de los bienes, determinándose que salvo error grave o falsedad, una vez hecho el reparto de los bienes no se pueda deshacer sin motivo justificado:

La particion que ficieren los hermanos o los parientes daquello que heredan, non sea despues desfecha por ninguna manera, maguer non aya y escripto, si pudiere seer provado por testimonias. Et esto debe seer de los que son de hedat complida. Ca si por

\footnotetext{
46 Por ejemplo, en este caso concreto, encontramos en el código alfonsí dos disposiciones diferentes, contenidas en dos Partidas distintas, referidas a las ganancias generadas por la gestión realizada por parte de uno de los hermanos de los bienes de los padres:

P, III, IX, LEY I: "Por quántas razones pueden seer puestas las cosas que otro tenga en mano de fiel, et quales deben seer los fieles. La quinta es quando algunt home ó muger que hobiese dos fijos, non se acordando del uno dellos nin faciendo mención dél á su finamiento, otorgase todos sus bienes al otro dcxándolo por su heredero en todo, ó si se acordase dél et lo desheredase sin derecho; ca tal fijo como este bien puede demandar á su hermano la parte que debie haber de los bienes de su padre ó de su madre, queriendo él meter á particion con ese su hermano todas las ganancias que fizo con los bienes de aquel su padre ó su madre: et si fuere muger que meta otrosi á particion la dote quel fue dada á su casamiento, ó que la descuente en la su parte de aquellos bienes que quiere heredar et que dé fiadores al otro hermano que todas estas cosas traerá á particion bien et lealmente et que non fará hi ningunt engaño; et faciendo esto debe venir con su hermano á particion de los bienes: et si esto non quyisicre facer, debe seer metida toda la su parte de los bienes que él debie heredar en mano de fiel que gela guarde et recabde los frutos della: et debel seer dado plazo del judgador á que faga todas estas cosas, et si fasta aquel plazo las compliere, debe el judgador mandarle dar et entregar toda su parte con los frutos que della salieren, et si non débelo todo mandar tornar al otro su hermano que fue establescido por heredero de aquellos bienes".

P, VI, XV, LEY III: "De quáles ganancias es tenudo el un hermano de dar parte al otro. Todas las cosas que el fijo ganare en mercadoria con el haber de su padre seyendo en su poder, todas las debe adocir á particion con los otros bienes que fueron de su padre,et partirlas con los otros sus hermanos. Otrosi decimos que la dote ó el arra ó la donacion que el padre diere en casamiento á alguno de sus fijos ó de sus fijas, se debe contar en la parte daquel á quien fue dada, fueras ende si el padre dixiese señaladamiente quando gela daba ó en su testamento que non querie que gela contasen en su parte. Et esto ha logar quando los hermanos tan solamienre heredan los bienes de su padre ó de su abuelo, mas si otro extraño fuese con ellos establescido por heredero, entonce las ganancias sobredichas, ó las donaciones ó dotes que fuesen dadas á los hermanos, non las deben meter á particion con los extraños nin las deben contar en su parte con ellos".
} 
aventura alguno daquellos que parten o reciben parte, non fuer de hedat, maguera sea fecha la particion, cuando fuer de hedat, si algun engaño fallare en la particion, bien la pueda desfacer si quisiere $^{47}$.

Eso sí, uno de esos motivos justificados a la hora de deshacer el reparto era la ausencia del heredero legítimo de la localidad en el momento del fallecimiento de los progenitores. Así, en la misma recopilación legislativa figura una ley que estipula expresamente que también deben ser tenidos en consideración los hermanos que hubieran salido de la localidad de residencia:

Si a la ora que moriere el padre e la madre, o qualquier dellos, alguno de los fijos non fuere en la tierra, e el otro fijo que y fuer tomar e se apoderar de la buena que les pertenesce por herencia, quando quier que viniere el hermano que non era en la tierra, entre en aquella buena, e non le pueda decir el hermano que ante se apoderó, que salga de aquella buena por que él era tenedor, mas tenganla de souno fasta que la partan. Et esto mismo sea de la herencia que les vinier de a vuelo o de .a vuela, o de otra pane que an derecho de heredar de consouno ${ }^{48}$.

Otro de los elementos que desde temprano se van instalando en la práctica jurídica y social de la época es la de la toma en consideración de la dote y las arras otorgadas con motivo del matrimonio a la hora de establecer el reparto de la herencia ${ }^{49}$ :

Toda cosa que el padre o la madre diere a alguno de sus hijos en casamiento, sea el fijo tenudo de lo adocir a particion con los otros hermanos despues de la muerte del padre o de la madre que gelo dio: et si amos gelo dieren de consouno, e el uno dellos moriere, el fijo sea tenudo de tornar a particion la meytad de lo quel dieron en casamiento, e si amos morieren, tome todo quantol dieron a particion con los hermanos ${ }^{50}$.

A lo largo de los siglos XIV y XV se irá produciendo un proceso de asimilación de la dote a la legítima de la mujer ${ }^{51}$, que parte de este mismo principio conceptual ya recogido por el Fuero Real, en el que se computan todos los bienes recibidos por los hermanos de sus progenitores, ya sea en vida de

47 FR, III, IV, 8.

48 FR, III, VI, 8.

49 A este respecto véase $\mathrm{M}^{\mathrm{a}} \mathrm{F}$. Gámez, Régimen juridico de la mujer; $\mathrm{M}^{\mathrm{a} J}$. Collantes de Terán, El régimen económico del matrimonio; M.A. Bermejo, Transferencias patrimoniales.

50 FR, III, VI, 14.

51 I. Beceiro, R. Córdoba, Parentesco, poder y mentalidad. 
ellos o con motivo de su fallecimiento. Este principio será más desarrollado en legislaciones posteriores, como las Partidas ${ }^{52}$.

Ya hemos visto a la hora de explorar la definición del vínculo fraternal cómo una de las escasas menciones al respecto se refería a la relación de parentesco establecida entre dos personas que sólo compartieran uno de los dos progenitores. Ello se debe, sin duda, a la importancia que esta cuestión tenía a la hora de determinar la herencia a repartir. Por ello, las referencias son muy tempranas, apareciendo ya en el Fuero Real la siguiente disposición:

Quando el ome que oviere fijos de una muger, casar con otra que ovier fijos de otro marido, e si amos ovieren fijos de consouno, si el marido o la muger muriere, los fijos que fueren de aquel muerto partan comunalmiente toda su buena. Et si alguno de los hermanos que fueren de padre e de madre moriere sin heredero e manda non ficiere, los otros sus hermanos que fueren de padre e de madre hereden toda su buena, e si fueren hermanos de seños padres o de señas madres, cada uno de los hermanos herede la buena de su hermano quel vino del padre o de la madre de que son hermanos. Et si algunas ganancias fizo el muerto de otra parte, los otros sus hermanos parianlas de consouno comunalmientre ${ }^{53}$.

52 Más concretamente en dos leyes diferentes:

P, IV, VII, LEY IV. "Cómo las donaciones que el padre face en su vida á algunt su fijo, si deben seer contadas en su parte ó non. En su vida faciendo donacion el padre á su fijo que estodiere en su poder, si despues non la revocare fasta su muerte, este fijo atal habrála donacion que desta guisa fuere fecha libre et quita, et non gela pueden contar en su parte los otros hermanos en la particion, fueras endesi el padre hobiese dado en casamiento á los otros hermanos alguna cosa segunt que dice en la ley ante desta. Ca si este fijo atal quisiere contar á los otros hermanos en sus partes las donaciones que les el padre ficiera en razon de casamiento, entonce decimos que sea otrosi contada en su parte la donacion que el padre fizo á él en su vida, et esto es porque sea guardada egualdat entrellos. Pero si el padre ficiese tan grant donacion al uno desus fijos que los otros sus hermanos non podiesen haber la su parte legítima en lo al que fincase, decimos que entonce deben minguar tanto de lo de la donacion fasta que puedan seer entregados los otros hermanos de la su parte legítima que deben haber".

P, IV, VII, LEY VI. "Cómo la dote ó el arra que rescibe el padre por su fijo ó por su fija non debe venir á particion entre, los otros hermanos. Dote ó arra seyendo dada de otro al padre por razon de casamiento de su fijo ó de su fija, aquello quel fuese dado en esta manera ensalvo finca al fijo d'á aquella fija por quien fue dada, et nol pueden demandar parte della los otros hermanos nin la deben haber; et esto es por el encargo quel finca de mantener el casamiento con aquella dote, et por que tales bienes non es tenudo de partir el hermano nin lahermana con los otros. Mas si el padre diese dote por su fija ó por su fijo, ó ficiese donacion ó arras a su muger, entonce debe seer guardado lo que dixiemos desuso en la ley que comienza: Todas las cosas. Otrosí decimos que si el fijo ficiese algunas debdas en vida del padre por su mandado ó que se tornaron en pro dél, que tales debdas como estas deben seer pagadas comunalmiente de los bienes de laheredat del padre. Et aun decimos que si alguno de los herederos rescibiese los frutos de la heredat, que tenudo es de los adocir á particionentre los otros herederos, et si algunas despensas fizo á pro de la heredat ó en coger los frutos, debe seer entregado dellas, et lo al que finca deben partir entre sí como sobredicho habemos".

53 FR, III, VI, 12. 
Alguna disposición similar aparece también en las Partidas ${ }^{54}$, y me sirve además para introducir un último aspecto referido a las herencias de gran trascendencia para la época. Como se puede observar en el desarrollo de estas leyes, aparece con mucha asiduidad la posibilidad de que el fallecido no deje testamento. Este documento, profusamente utilizado por la historiografía de las mentalidades en las últimas décadas para analizar todo el entorno de la muerte y sus circunstancias ${ }^{55}$, también tiene una evidente connotación de tipo patrimonial, ya que se trata de los documentos que recogen las últimas disposiciones en vida de un particular, y nos permite recrear a partir de ellos su patrimonio, relaciones familiares, devociones religiosas, etc. ${ }^{56}$.

Pero, a pesar de la insistencia en la conveniencia de testar y las disposiciones referidas al modo en que debían hacerse, en muchas ocasiones se producía el fallecimiento de la persona sin que ésta hubiera dejado constancia de sus últimas voluntades, lo que generaba un problema jurídico con respecto a su patrimonio que había que solucionar. Este hecho, que en condiciones normales generaba situaciones de conflicto ${ }^{57}$, se agudizaba sobre manera cuando

54 P, VI, XIII, LEY VI. "Hermanos de padre tan solamente, e otro de madre, auiendo aquel que muriesse sin testamento, si non dexasse otro pariente ninguno, que eredasse lo suyo. Hermanos de padre tan solamente, e otro de madre, auiendo aquel que muriesse sin testamento, si non dexasse otro pariente ninguno, que eredasse lo suyo, de los que descienden, o suben, por la liña derecha; estonce dezimos, que en tal caso como este, el hermano que le pertenesciesse a este atal de padre tan solamente, esse eredara todos los bienes del defunto, que le vinieren de parte de su padre: e el hermano que le pertenesciesse de parte de la madre, esse eredara otrosi lodos los bienes que le vinieren de parle de su madre: e los bienes que atal defunto como este ouiesse ganado por otra manera qualquier, amos los hermanos sobredichos los partiran egualmente. E sobre todo esto dezimos, que si alguno muriesse sin testamento, que non ouiesse parientes, de los que suben, o descienden por la liña derecha, nin ouiesse hermano, nin sobrino lijo de su hermano; que destos adelante, el pariente que fuere fallado que es mas cercano del defunto fasta en el deceno grado, esse eredara todos sus bienes. E si tal pariente non fuesse fallado, e el muerto auia mujer legitima quando fino, eredara ella todos los bienes de su marido; esso mismo dezimos del marido, que eredara los bienes de su mujer, en tal caso como este. E si por auentura, el que assi muriesse sin parientes non fuesse casado, estonce eredara todos sus bienes la Camara del Rey".

55 Para una reciente revisión historiográfica del tema véase D. Baloup, La mort au Moyen Âge.

${ }^{56}$ Desde que Michel Vovelle planteó su trabajo paradigmático sobre Provenza, han sido muchos los trabajos dedicados al estudio del universo social que rodea a los testamentos en el medievo hispano, con desigual ambición metodológica. Sirva de referencia el siguiente listado de títulos, en los que encontrará el lector diversas propuestas para distintos contextos peninsulares bajomedievales: M. Vovelle, Piété baroque et déchristianisation en Provence au XVIIIe; J. Casamitjana, El testamento en la Barcelona bajomedieval; M.L. Rodrigo, Testamentos medievales aragoneses; A. García, Actitudes ante la muerte; L. Ruiz, Testamento, muerte y religiosidad en la Yecla; A. Bejarano, El hombre y la muerte; $\mathrm{M}^{\mathrm{a}} \mathrm{C}$. Carlé, Una sociedad del siglo XV; M.M. García, La religiosidad de los jerezanos. A todos estos libros hay que añadirles un importante número de artículos y comunicaciones a congresos elaboradas por estos y otros autores.

57 Que requirió leyes concretas en las Partidas destinadas a regular el procedimiento de reparto de la herencia, en el que, como se puede observar, el papel de los hermanos es fundamental: P, VI, XIII, LEY V: "Fasta aqui mostramos en que manera los ascendientes, é descendientes 
el fallecido dejaba descendencia de dos uniones diferentes, por lo que la regulación exigida al respecto es mayor si cabe ${ }^{58}$.

Establecidas estas cuestiones relativas a la obligación del reparto de la herencia, a partir de ese punto la propia legislación reconoce una serie de situaciones conflictivas en torno a esta distribución patrimonial. Si la transmisión de la herencia era obligatoria, según se desprende de las disposiciones recogidas con anterioridad, se hacía necesario regular aquellos supuestos en los que esa obligatoriedad no debía cumplirse. En lo que atañe a las relaciones fraternales, las Partidas recogen una ley titulada, explícitamente, Cómo puede el home desheredar á sus hermanos con razon ó sin ella, lo que da pistas indudables sobre su contenido ${ }^{59}$. En este caso el vínculo fraternal se proclama en el momento

deben heredar entre si, cuando alguno de ellos muriere sin testamento. E agora queremos decir, como pueden heredar entre si, los que son de la liña dicha, de travieso; asi como los hermanos, é los tios, á los otros parientes que son en aquella liña, muriendo alguno dellos sin testamento. Et decimos, que si alguno que asi muriese sin testamento, non oviese de los parientes que suben, ó descienden por la liña derecha, é oviese hermano, ó hermana de padre, á de madre, ó sobrino fijo de tal hermano, ó de tal hermana que fuese ya muerta; que el hermano, é el sobrino heredan los bienes de tal defunto egualmente: e maguer sean les sobrinos dos, ó mas, nascidos de un hermano, ó de hermana, non auran mas de la, metad de la heredad, é partirla han ellos entre si por cabezas egualmente. Mas si este que muriese sin testamento non aviendo ascendientes, nin descendientes, oviese sobrinos de dos hermanos de parte de su padre, ó de su madre, é fuesen los hermanos amos muertos, heredarán los sobrinos los bienes de su tio, é partirlos han entre si por cabezas egualmente. E sobre todo decimos, que si este que asi muriese, oviese otros hermanos que non le perteneciesen si non de parte de su madre, ó de su padre, que estos, nin los fijos dellos, non deben aver herencia del finado con los hermanos que le pertenecen de parte de padre é madre, nin con los fijos deüos, si los padres fuesen muertos".

58 Por ello, además de la ley ya mencionada del Fuero Real, también en las Partidas se dedicó una ley a determinar este punto: "Hermanos de padre tan solamente, e otro de madre, auiendo aquel que muriesse sin testamento, si non dexasse otro pariente ninguno, que eredasse lo suyo" (P, VI, XIII, LEY VI).

59 P, VI, VII, LEY XII. "Las razones por que pueden seer desheredados los parientes que descenden et suben por la liña derecha mostramos fasta aqui, et agora queremos mostrar en qué manera pueden seer desheredados los que estan en la liña de travieso, asi como los hermanos, et decimos que el un hermano puede desheredar al otro con razon et sin razon, et aunque non ficiese mencion del en el testamento, puede dexar lo suyo á quien se quisiere quando non hobiere fijos nin otros parientes que descendiesen del nin padre nin abuelo, fueras ende si establesciese por su heredero á tal home que fuese de mala vida ó enfamado; ca entonce non valdrie el establescimiento de tal heredero, ante decimos que el hermano puede quebrantar el testamento et haber la heredat de su hermano, probando esto ante el judgador asi como debe. Empero tres razones son por que non se quebrantarie tal testamento en que el hermano hobiese establescido su heredero, maguer fuese enfamado de mala vida: la primera es si el testador hobiese desheredado á aquel su hermano por razon que se hobiese trabajado de su muerte en alguna manera. La segunda es si en algunt tiempo le hobiese acusado criminalmiente á muerte ó á perdimiento de miembro. La tercera es sil hobiese fecho perder la mayor partida de sus bienes, et aunque los non perdiese, si non fincó por él de gelos facer perder; ca por qualquier destas tres razones sobredichas que fuese averiguada puede el un hermano desheredar al otro, maguer establesciese por su heredero á home mal enfamado. Et aun decimos que si pudiere seer probado que el hermano erró contra el otro en alguna de lastres maneras que deximos, que si el hermano á quien es fecho el yerro moriese sin testamento, non podrie el otro que habie errado contra él demandar nin heredar ninguna cosa de los bienes del por razon del parentesco". 
en el que una persona considera que su hermano ha incumplido algunas de las razones para disfrutar de la herencia paterna, lo que en determinados supuestos permitiría el incumplimiento de ese testamento y el retorno de los bienes a la línea transversal de la parentela. Las normas son tan exhaustivas, que se citan incluso tres ejemplos en los que este tipo de acusaciones no tendrían que tener validez: si el hermano previamente ha desheredado al otro, si ha intentado acabar con su vida, o si le ha causado un grave daño patrimonial. Hay, incluso, otras dos leyes que abundan en esa línea, destinadas a determinar con toda la fidelidad posible el margen de actuación en este tipo de situaciones ${ }^{60}$.

De todo este conjunto de leyes que involucran a la herencia y al vínculo fraternal me interesa destacar, más allá de los detalles de tipo jurídico, el exhaustivo tratamiento que recibe la transferencia patrimonial en la legislación castellana en la época. Si las leyes que se han citado son sólo aquéllas en las que la relación entre hermanos es un elemento determinante, resulta fácil imaginar el elevado número de disposiciones que en general regulaban el reparto de herencias y dotes.

Dentro de este tratamiento, el papel asignado a los hermanos fluctúa en unos términos parecidos a los que ya hemos visto para otras cuestiones. La relación fraternal genera derechos, pero también obligaciones, y se ve mediatizada por factores de tipo jurídico y económico de una manera evidente.

Como acabamos de comprobar las referencias más abundantes que encontramos en la legislación castellana bajomedieval a posibles conflictos entre hermanos se derivan del reparto de las herencias. Sin embargo, no quiero finalizar sin resaltar esos otros ámbitos de actuación en los que la legislación resaltaba la relación entre hermanos, esencialmente en aquellos casos encuadrados en ese tipo de conflictos de carácter externo a los que ya he hecho mención anteriormente. Así, por ejemplo, uno de los motivos por los que un hombre podía agredir de manera justificada a un clérigo era precisamente que hubiera "deshonrado" a su hermana ${ }^{61}$. Si ello ocurría el agresor podía evitar caer en excomunión.

También le otorgó la legislación castellana, desde los fueros y el Fuero Real, pasando por las Partidas y terminando en el Ordenamiento de Alcalá,

60 P, VI, VIII, LEY II: "Si puede el hermano quebrantar ó non el testamento que hobiese fecho su hermano en que non ficiese mencion dél"; P, VI, VIII, LEY III. "Por qué razones non puede el hermano quebrantar el testamento de su hermano, maguer establesciese su siervo por heredero".

61 P, I, IX, LEY III. "Quántas cosas son et quáles por que no son descomulgados los que meten manos iradas en clérigo (...) la séptima es si falla alguno al clérigo con su muger, o con su hija, ó con su madre ó con su hermana, que sil feriere non es descomulgado por ello". 
un papel esencial al hermano a la hora de tratar los rieptos o desafíos ${ }^{62}$. Esta fórmula medieval de solucionar los conflictos trataba de enmarcar la violencia generada por algún hecho significativo y limitar los posibles daños causados a los respectivos linajes de cada uno de los intervinientes en el delito que motivaba el riepto. En este juego de equilibrios, el papel del hermano era vital a la hora de retar al que había hecho algún tipo de injuria a su hermano ${ }^{63}$.

Otra de las fuentes de conflicto familiar en la época se relaciona estrechamente con la sexualidad. Ya he mencionado, en un apartado anterior, que el Fuero Real permitía a un padre matar sin pena al hijo que sorprendiera yaciendo con su hermana, lo que permite inferir lo que el incesto suponía para la sociedad de la época. En ese mismo contexto cultural también hay delitos castigados con penas menores, pero que relacionan la práctica sexual y la relación familiar, con especial énfasis en la fraternal:

Sy algun ome yoguiere con muger de su padre, faganle como a traydor, e si yoguiere con la barragana, faganle como a alevoso, e si yoguiere con muger de su hermano, o con su barragana, o con aquella, que sopiere que su padre o su hermano ha yacido, o si el padre yoguiere con la muger del fijo o con su barragana, el rey pues que lo sopiere echelos de la tierra por siempre, e sus bienes ayanlos sus herederos, e nunca sean pares dotros, nin puedan testiguar en ningun pleyto $^{64}$.

Eso sí, el mismo Fuero Real nos señala que uno de los eximentes del delito de asesinato es el sorprender al asesinado manteniendo relaciones sexuales con su hija o con su hermana ${ }^{65}$. Este espacio de la sexualidad refuerza los atribu-

${ }_{62}$ M. Madero, El riepto y su relación con la injuria; A. Otero, El riepto en los fueros municipales.

${ }^{63}$ FR, IV, XXV, 14: "Todo fidalgo pueda reptar a otro por fecho que caya en alep, que ficiere a él o a su sennor, o a su padre, o a su madre, o a fijo, o a fija, o a hermano, o a hermana, o a pariente, o a parienta por que deva acalonnar: et qui por otre reptare, aya la pena de la ley, e el reptado sea quito, mas guardese el reptador, que non riepte por ninguno de los sobredichos, si non por sennor, demientre que él por que riepta fuer vivo, ca non deve en riepto personero seer recebido, fueras si reptar por muger, o por ome de orden, o por tal que non pueda, o non deva tomar armas; ca bien queremos que por fecho que en tales ca ya, pueda reptar cada uno de sus parientes; maguer que sea vivo aquel por que repta".

OA, XXII, VII, LEY VII: "Establescemos que en esta manera se puedan facer los riebtos. Todo fijodalgo pueda rebtar por tuerto, é desonrra que caia en traicion, ó en aleve,que le aya fecho otro fijodalgo: esto que lo pueda él facer por si mismo, et si fuere muerto el que rescibiere la desonrra, pueda rebtar el padre por el fijo, é el fijo por el padre, é el hermano por el hermano".

64 FR, IV, VIII, 3.

65 FR, IV, XVII, 1. "Todo ome que matare a otro a sabiendas, muera por ello, si non si matare. su enemigo connoscido, o defendiéndose, o sil fallare yaciendo con su muger do quier quel falle, o sil fallare en su casa yaciendo con su fija o con su hermana, o sil fallare levando muger forzada para yacer con ella, o que aya yacido con ella, o si matare ladron quefallare de noche en su casa furtando o foradandola, o sil fallare con el furto fuyendo, e se quisier anparar 
tos que la legislación de la época daba al vínculo de hermandad a partir de otros supuestos. También en esta ocasión la figura de la hermana requiere protección, y aparece subordinada, y en muchas ocasiones equiparada, a la de la hija.

Por último, quiero mencionar el último conflicto de tipo violento que recoge la figura de los hermanos en la legislación castellana medieval, y que se refiere al asesinato en el seno de la familia. En esta ocasión se menciona en dos ocasiones. Por una parte, cuando se le incluye en el listado de relaciones de parentesco entre asesino y víctima en una posición preferente ${ }^{66}$. Pero, además, recoge la misma ley que el duro castigo que se cita merecerá el hijo que, conociendo que su hermano tiene la intención de asesinar a su padre, no actúe en consecuencia para detenerlo. Es interesante este detalle porque revela una zona oscura de conspiraciones entre hermanos para acabar con sus ascendientes que la ley trata de evitar, privilegiando de esta manera el vínculo vertical entre padres e hijos al horizontal de los hermanos.

Aunque se trata de una variante de conflicto que no tiene la misma representación en la documentación judicial que en los textos normativos, esta tipificación debe responder a algún tipo de miedo en la época, ya que hay otras referencias de tipo indirecto que nos sitúan en el mismo escenario. Por ejemplo, en el Fuero Viejo de Castilla se estipula en una extensa ley en qué condiciones los hermanos no han de sospechar de el que vivía con sus padres en el momento en el que ellos fallezcan ${ }^{67}$. Evidentemente, este tipo de detalles hay que ponerlos en relación con las cuestiones referidas a la herencia descritas en el apartado correspondiente.

de prision, o sil fallare forzando lo suyo, e non lo quisiere dexar, o si lo matare por ocasion non queriendo matarle nin aviendo malquerencia dante con el, o si lo matare acorriendo a su sennor, que vea matar o que quieren matar, o a padre, o a fijo, o avuelo o a hermano, o a otro ome que deva vengar por linage, o matar en otra manera que pueda mostrar que lo mató con derecho".

66 P, VII, VIII, LEY XII. "Qué pena meresce el padre que matare á su hijo, ó el hijo que matare su padre ó alguno de los otros parientes. Si el padre matare á su fijo, ó el fijo al padre, ó el abuelo al nieto ó al biznieto, ó alguno dellos á él, ó el hermano ó hermana á su hermano ó á su hermana, ó el tio al sobrino, ó el sobrino al tio".

${ }^{67}$ FVC, V, III, 8.: "Todo ome que a fijos, o fijas e vanse ellos fuera de casa por casamiento, o por al, e viene a tiempo, que muer el padre, o la madre, morando estos hijos con ellos, pueden los fijos de fuera, demandar partición de mueble, e de eredat, en quanto an ganado los fijos, que fincaron con el padre, o con. la madre. Mas a quien tal cosa como esto acaecier, salese con lo suo, e vayase a otra casa a morar ante que el padre o la madre muera; e si por aventura el padre, o la madre menoscabaren de lo suo, e vinieren a pobreça, e alguno de los fijos sea rico, e quier levar a suo padre, o a sua madre a casa, e facerle algund bien, e dijier a los otros ermanos, quel quiten, que si el padre, o la madre murier en su a casa, quel non demanden particion, e los otros non le quieren quitar, por eso non deve dejar de facer bien al padre, o a la madre, e de levar lo a su a casa; e a la ora que los ouier de levar deve llamar los Alcalles, e los omes bonos, que vean lo que levan a suas casas con el padre, o con la madre, e esto faciendo non le deven los ermanos tener de lo suo, porque muera el padre, o la madre en sua casa. E este es Fuero de Castiella: que si muer el padre, o madre en casa del fijo non le an porque demandar los otros ermanos ninguna cosa por tal raçon". 


\section{CONCLUSIONES}

Con esta última mención finaliza esta revisión de los límites culturales de las relaciones entre hermanos a partir de la legislación castellana bajomedieval. Como hemos ido viendo, hay muchos aspectos que no son tratados con profusión en las distintas leyes que regularon la vida jurídica de la Castilla de la época. En realidad, las definiciones de hermandad parten más de sobreentendidos de diverso tipo que de menciones en los distintos corpora jurídicos. Se entiende que los hermanos tienen, por la propia naturaleza de sus lazos consanguíneos, relaciones de amor totalmente alejadas de toda sospecha de tipo moral. Cuando el padre fallece es el hermano mayor el que se ha de hacer cargo de los menores, y cuando alguno de los miembros del grupo familiar es afrentado por alguien externo tiene un papel reservado de gran importancia. En todos estos casos, la relación de hermandad, transversal, reproduce la vertical ubicando al primogénito varón en el lugar del padre desaparecido.

Sin embargo, esta teórica buena relación no encaja plenamente con lo que se recoge en las variadas disposiciones referidas a la herencia que se tratan en la legislación. En ellas encontramos una amplia casuística de posibilidades de conflicto patrimonial entre hermanos, que además tuvo amplia correspondencia con lo que posteriormente quedaría consignado en los archivos como vestigios de una actividad judicial que tuvo especial trabajo en resolver los pleitos por herencias que, en muchas ocasiones, enfrentaban a los hermanos entre sí.

En resumen, este análisis de la carga conceptual asignada por la legislación al vínculo fraternal permite definir con cierta precisión unos límites culturales que, sin duda, debieron influir en los comportamientos en el seno del grupo familiar. Pero, como indicaba al introducir el tema, que la legislación tratara de generar unas relaciones positivas entre hermanos, y definiera con la mayor precisión posible los distintos conflictos que podían generar problemas, no implicaba que los hermanos siempre tuvieran relaciones cordiales. Los fondos de archivos judiciales dan buena fe de ello.

\section{BIBLIOGRAFÍA CITADA}

Alvarado Planas, Javier; Montes Salguero, Jorge J.; Pérez Marcos, Regina $\mathrm{M}^{\mathrm{a}}$.; Sánchez González, Ma . Dolores del Mar, Manual de Historia del Derecho y de las Instituciones, Madrid, Sanz y Torres, 2006.

Aurell, Martin (Ed.), La Parenté déchirée: les luttes intrafamiliales au Moyen Âge. Turnhout, Brepols, 2010

Baloup, Daniel, La mort au Moyen Âge (France et Espagne). Un bilan historiographique, en Mínguez, César; Bazán, Iñaki (dirs), El discurso 
legal ante la muerte durante la Edad Media en el nordeste peninsular, Bilbao, Universidad del País Vasco UPV/EHU, 2006, pp. 13-32.

Beceiro Pita, Isabel; Córdoba de la Llave, Ricardo, Parentesco, poder y mentalidad. La nobleza castellana. Siglos XII-XV. Madrid, CSIC, 1990.

Bejarano Rubio, Amparo, El hombre y la muerte: los testamentos murcianos bajomedievales, Cartagena, Ayuntamiento de Cartagena, 1990

Bermejo Castrillo, Manuel Ángel, Transferencias patrimoniales entre los cónyuges por razón del matrimonio en el derecho medieval castellano, en Iglesia Duarte, José Ignacio de la (coord.), La familia en la Edad Media. XI Semana de Estudios medievales, Logroño, IER, 2001. pp. 93-150.

Bernardsky, S., Keeping It in the Family? Domestic Violence in the Later Middle Ages: Examples from a Provençal Town (1340-1403), en Davis, Isabel; Müller, Miriam; Rees Jones, Sarah (eds.), Love, Marriage and Family Ties in the Later Middle Ages, Turnhout, Brepols, 2003, pp. 277-297. (International Medieval Research; 11).

Bestard, Joan; Chacón Jiménez, Francisco (dirs.), Familias: historia de la sociedad española. Del final de la Edad Media a nuestros días, Barcelona, Crítica, 2011.

Brozyna, Martha A., Not Just a Family Affair: Domestic Violence Not Just a Family Affair: Domestic Violence en Davis, Isabel; Müller, Miriam; Rees Jones, Sarah (eds.), Love, Marriage and Family Ties in the Later Middle Ages, International Medieval Research 11, Turnhout, Brepols, 2003, pp. 299-310.

Brundage, James A., La ley, el sexo y la sociedad cristiana en la Europa medieval, México DF, FCE, 2000.

Calderón Medina, Inés, "Cum Magnatibus Regni Mei”. La nobleza y la monarquía leonesas durante los reinados de Fernando II y Alfonso IX (1157-1230), Madrid, CSIC, 2011.

Carlé, $\mathrm{M}^{\mathrm{a}}$ Carmen, Una sociedad del siglo XV: los castellanos en sus testamentos, Buenos Aires, Universidad Católica Argentina, 1993

Casamitjana i Vilaseca, Jaume, El testamento en la Barcelona bajomedieval: la superación de la muerte patrimonial, social y espiritual, Pamplona, EUNSA, 2004.

Casey, James, La conflictividad en el seno de la familia, "Estudis" 22 (1996), pp. 9-25.

Collantes de Terán de la Hera, $\mathrm{M}^{\mathrm{a}}$ José, El régimen económico del matrimonio en el derecho territorial castellano, Valencia, Tirant lo Blanch - Cádiz, Servicio de Publicaciones de la Universidad de Cádiz, 1997.

Dacosta Martínez, Arsenio, Los linajes de Bizkaia en la Baja Edad Media: poder, parentesco y conflicto, Bilbao, Servicio Editorial Universidad del País Vasco UPV/EHU, 2003. 
Davis, Isabel; Müller, Miriam; Rees Jones, Sarah (eds.), Love, Marriage and Family Ties in the Later Middle Ages, International Medieval Research 11, Turnhout, Brepols, 2003.

Diago Hernando, Máximo, El papel de los linajes en las estructuras de gobierno urbano en Castilla y en el Imperio alemán durante los siglos bajomedievales, "En la España Medieval” 20 (1997), pp. 143-177.

Díaz de Durana Ortiz de Urbina, José Ramón, La familia en la cornisa cantábrica al final de la Edad Media, en Lorenzo Pinar, Francisco Javier, La familia en la Historia, Salamanca, Universidad de Salamanca, 2009, pp. 63-88.

Duby, Georges ; Le Goff, Jaques (dirs.), Famille et parenté dans l'Occident médiéval. Actes du colloque de Paris (6-8 Juin 1974), Roma, École Française, 1977.

El Fuero Viejo de Castilla, sacado y comprobado con el ejemplar de la misma obra que existe en la real biblioteca de esta corte, y con otros mss, Madrid, Libr. de viuda e hijos de Antonio Calleja, 1847.

El ordenamiento de leyes que D. Alfonso XI hizo en las Cortes de Alcalá de Henares el año de mil trescientos y quarenta y ocho, Madrid, Libr. de viuda e hijos de Antonio Calleja, 1847.

Gámez Montalvo, $\mathrm{M}^{\mathrm{a}}$ Francisca, Régimen juridico de la mujer en la familia medieval castellana, Granada, Comares, 1998.

Ganghofer, Roland (dir.), Le droit de la famille en Europe, son évolution depuis l'Antiquité jusqu'à nos jours, Estrasburgo, Presses Universitaires de Strasbourg, 1992.

García González, Francisco (ed.), Historia de la familia en la Península Ibérica: balance regional y perspectivas: Homenaje a Peter Laslett, Cuenca, Universidad de Castilla La Mancha, 2008. Disponible on-line: http:// www.uclm.es/seminarios/sehisp/libro.asp, [consulta: 01/03/2012].

García Guzmán, $\mathrm{M}^{\mathrm{a}}$ del Mar, La religiosidad de los jerezanos según sus testamentos (siglo XV), Cádiz, Agrija Ediciones, 1997.

García Pedraza, Amalia, Actitudes ante la muerte en la Granada del siglo XVI: los moriscos que quisieron salvarse, Granada, Universidad de Granada, 2002

Gerbet, Marie-Claude, La nobleza en la corona de Castilla: sus estructuras sociales en Extremadura (1454-1516), Cáceres, Institución Cultural "El Brocense", 1989.

Gerbet, Marie-Claude, Las noblezas españolas en la Edad Media, ss. XI-XV, Madrid, Alianza Editorial, 1997.

González Zalacain, Roberto J., La familia en Castilla en la Baja Edad Media: violencia y conflicto, Madrid, Congreso de los Diputados, en proceso de edición. 
Guerreau-Jalabert, Anita, Sur les structures de parenté dans l'Europe médiévale, "Annales. Economies, Sociétés, Civilisations" 36/6 (1981), pp. 1028-1049.

Guerreau-Jalabert, Anita, El sistema de parentesco medieval: sus formas (real/espiritual) y su dependencia con respecto a la organización del espacio, en Pastor, Reyna (comp.), Relaciones de poder, de producción y de parentesco en la Edad Media y Moderna, Madrid, CSIC, 1990, pp. 85-105.

Hoppenbrouwers, P.C.M., Vengeance Is Ours? The Involvement of Kin in the Settlement of 'Cases of Vengeance' in Later Medieval Holland, en Davis, Isabel; Müller, Miriam; Rees Jones, Sarah (eds.), Love, Marriage and Family Ties in the Later Middle Ages, Turnhout, Brepols, 2003, pp. 241-276. (International Medieval Research; 11).

Howard, Matthew, 'We are broderen': Fraternal Bonds and Familial Loyalty within the Fifteenth-Century Romance of Generydes, en Davis, Isabel; Müller, Miriam; Rees Jones, Sarah (eds.), Love, Marriage and Family Ties in the Later Middle Ages, Turnhout, Brepols, 2003, pp. 129-142. (International Medieval Research; 11).

Iglesia Duarte, José Ignacio de la (coord.), La familia en la Edad Media. XI Semana de Estudios medievales, Logroño, IER, 2001.

Las Siete Partidas del Rey Don Alfonso El Sabio, cotejadas con varios códices antiguos por la Real Academia de la Historia, Madrid, Imprenta Real, 1807.

Lett, Didier, Frères et sæurs. Histoire d'un lien, París, Payot, 2009.

Lett, Didier, Les frères et les soeurs, "parents pauvres» de la parenté, "Médiévales" 58/1 (2008) pp. 5-12.

Madero, Marta, El riepto y su relación con la injuria, la venganza y la ordalía (Castilla y León, siglo XIII y XIV), "Hispania” 47/3 (1987) pp. 805-862.

Martínez Gijón, José, En la definición de hijo natural. De las Leyes de Toro de 1505 al Código Civil de 1889, Sevilla, Universidad de Sevilla, 1992.

Martínez Sopena, Pascual, La prosopografía de la nobleza castellano-leonesa en los siglos XI-XIII. Balance y perspectivas, en La prosopografía como métido de investigación sobre la Edad Media. Sesiones de Trabajo (Seminario de Historia Medieval), Zaragoza, Universidad de Zaragoza, 2006, pp. 119-143.

Martínez Sopena, Pascual, La aristocracia hispánica. Castilla y León (siglos XI-XIII), "Bulletin du centre d'études médiévales d'Auxerre", [en línea], Hors série 2 (2008) http://cem.revues.org/index10052.html [consulta: 12/03/2012]

Monsalvo Antón, José María, Parentesco y sistema concejil. Observaciones sobre la funcionalidad política de los linajes urbanos en Castilla y León, "Hispania" 53/3 (1993) pp. 937-969. 
Montanos Ferrín, Emma, La familia en la Alta Edad Media española, Bilbao, EUNSA, 1980.

Morán Martín, Remedios, Materiales para un curso de Historia del Derecho, Madrid, UNED, 2010.

Müller, Miriam, Conflict, Strife, and Cooperation: Aspects of the Late Medieval Family and Household, en Davis, Isabel; Müller, Miriam; Rees Jones, Sarah (eds.), Love, Marriage and Family Ties in the Later Middle Ages, Turnhout, Brepols, 2003, pp. 311-330. (International Medieval Research; 11).

Muñoz Gómez, Víctor, La participación política de las elites locales en el gobierno de las ciudades castellanas en la Baja Edad Media. Bandos y conflictos de intereses (Paredes de Nava, final del s. XIV-inicio del s. XV), "Anuario de Estudios Medievales" 39/1 (2009), 275-305.

Opúsculos legales del rey Alfonso X el Sabio, publicados y cotejados con varios códices antiguos por la Real Academia de la Historia. Vol. 1: El espéculo o espejo de todos los derechos; Vol. 2: El fuero real, Madrid, Imprenta Real, 1836.

Otero Varela, Alfonso, El riepto en los fueros municipales, "Estudios histórico-jurídicos" 1 (2005) pp. 173-260.

Pastor, Reyna (comp.), Relaciones de poder, de producción y de parentesco en la Edad Media y Moderna, Madrid, CSIC, 1990.

Pastor, Reyna; Alfonso Antón, Isabel; Rodríguez López, Ana; Sánchez León, Pablo, Poder monástico y grupos domésticos en la Galicia foral (Siglos XIII-XV). La Casa. La Comunidad, Madrid, CSIC, 1990.

Rodrigo Estevan, $\mathrm{M}^{\mathrm{a}}$. Luz, Testamentos medievales aragoneses: ritos y actitudes ante la muerte (siglo XV), Zaragoza, Ediciones 94, 2002

Ruiz Molina, Liborio, Testamento, muerte y religiosidad en la Yecla del siglo XVI, Murcia, Ayuntamiento de Yecla, 1995

Solórzano Telechea, Jesús Ángel, Linaje, comunidad y poder: desarrollo y consolidación de identidades urbanas contrapuestas en la Castilla bajomedieval, en Familia y sociedad en la Edad Media (siglos XII$X V)$. Aragón en la Edad Media. Sesiones de trabajo, Zaragoza, Universidad de Zaragoza, 2007, pp. 71-94.

Vovelle, Michel, Piété baroque et déchristianisation en Provence au XVIIIe siècle: les attitudes devant la mort d'après les clauses des testaments, Paris, Seuil, 1978.

Fecha de recepción del artículo: marzo 2012

Fecha de aceptación y versión final: octubre 2012 